The aids to easy and accurate punching are twofold. For as many programmes as practicable, proformas are prepared where card columns are identified and the entries to be made in each group of columns corresponding to the value of a variable are clearly defined. Fig. 3 gives a typical proforma used for the closed circuit respiration chamber programme, $\mathrm{CCRC}_{3}$. Note that the decimal points are not punched but are clearly marked on the proforma. As mentioned above, a programme VIEW may be applied to any data so that a print-out is obtained of the data punched on a deck of cards. This is particularly useful for large decks of cards which are to be processed by lengthy programmes, as it prevents unnecessary waste of computer time.

In recent months we have noted with the increase in proforma use that an increasing proportion of punching is carried out by members of Biometry staff. Currently a scheme is being developed to process all the pig herd records by computer, and there is a throughput of about 3000 pigs annually. If this is successful the scheme will be extended to the other farm animals, in which event we shall probably increase our strength by one punch operator and shall then do virtually all punching within the Biometry Department. If this happens it is quite possible that a change will be made to the use of punch and verifier.

\title{
Diet assessment and formulation in human nutrition
}

\author{
By D. S. Miller and Pamela Mumford, Queen Elizabeth College, London, W8
}

Our paper is essentially a pragmatic one. We doubt if we can impress programmers on programming or nutritionists on nutrition. What we can try to do is to show how we have applied computing to our nutritional problems and hope that our experiences might be useful to others in similar circumstances. However, in order to avoid presenting simply a list of programmes which we have found successful we have attempted to draw out some general principles of approaching nutritional problems in which one can use a computer, and to outline our philosophy for criticism and discussion.

\section{Training and operation}

Some years ago we became interested in the results of gluttony in man, and we decided to overfeed ourselves. This involved determining our nutrient intake for a period of 20 weeks, and one of us was forced to spend half her time in calculating only four nutrients. We planned to call for at least twelve volunteers to extend the work, and it was quite clear we were not going to be able to do the calculations with our personnel. It is true that we could have designed our experiment in a way that all subjects were fed an indentical diet thereby reducing the arithmetic, but the extent of overfeeding each individual would have been different depending upon 
their normal intakes which varied from 2000 to $4000 \mathrm{kcal} /$ day. Also the capacity for overeating varied considerably and was determined to some extent by competition but also on a free selection of foods. Thus not only could we not have undertaken the work without a computer, but it gave us more freedom in experimental design.

At this time we were victims of the computer mystique and imagined that these devices were for nuclear physicists and space technologists and could only be operated by expert mathematicians. We now realize that computers are merely obedient idiots capable of doing dull arithmetic quickly, rather than free-thinking geniuses able to correct obvious errors. Our training involved only a $3 \mathrm{~d}$ course and a good deal of fun experimenting by trial and error. In this way any curious results were due to our own mistakes in programming and could be corrected by us. We consider it more efficient for biologists to learn to programme rather than for them to attempt to explain their problems to professional programmers, particularly as computer languages are becoming more simple. This may be seen when programmes have to be modified to accommodate minor alterations in the input data. Metrication will involve the use of different units of measurement, which is a trivial problem for those knowing something about computers, but an obstacle causing long delays for those tied to rigid and expensive programmes written by professionals. For example, we have a short programme that not only converts archaic British units for heights and weights into metric but at the same time calculates metabolic body weight $\left(\mathrm{kg}^{0.75}\right)$ and percentage average weight and height.

The difficulties of programming and operating computers have been overemphasized and are largely imaginary. This derives from the professional view that all operators begin with learning computer mechanics and basic languages, e.g. machine code, whereas it is already possible to instruct machines verbally and almost orally. Several of our colleagues are now writing programmes with virtually no training, having merely studied our efforts in conjunction with an operating manual.

Similarly we consider that biologists should operate the computer for themselves on an open shop plan. As members of London University we are entitled to use Atlas, although in fact we use the medium sized Elliot machines which are slower. Our decision is based on the fact that the speed of Atlas is largely illusory because there are too many people between us and the machinc. Using our own computer we can refine programmes in an afternoon whereas each error on Atlas involves an overnight courier service and an inevitable delay at the centre. It is rather like using Concorde to get from London to New York with a traffic jam on the way to the airport. We can get all the data required into the stores of the smaller machines, and for some problems we could manage with an electronic desk calculator with a small backing store. A computer in the laboratory would have many advantages, and judging from what went into the moon landing craft this could be quite compact.

\section{Diet assessment}

We have a standard method for collecting dietary information from our experimental subjects and a versatile battery of programmes which can deal with a wide 
range of problems. In other words, the input data are in the same form for a number of different short programmes which may be selected as appropriate. Also, the output from all programmes is in a form that can be used as input data for statistical and other processing.

We give our subjects books in which they record the description of the food, together with the weighed quantity that they have eaten. We then code the foods numerically. Our library of food composition data is based on those of McCance \& Widdowson (I 960 ) who conveniently numbered each food. To their $66_{3}$ foods we have since added many more covering a range of needs from vegans to zoo animals. It seems to us unnecessary to argue the relative merits of different food tables when some problems are more adequately served by one rather than another, since it is no problem to feed the computer with all available data. This is of value to the coder who has a wide selection of foods to choose from. If standardization is necessary it rests on the range of analyses presented. After all, one cannot instruct a machine to deal with 'don't know' or 'trace' values. We understand that new British food tables are to be published in both book and tape form, and it is to be hoped that the authors will deal with this problem and morcover retain the present code numbers to avoid confusing present users. It cannot be overemphasized that the precision of the whole exercise depends upon (a) the accuracy of the weighing, (b) the accuracy of the analysis, and (c) the skill of the coder. Such considerations apply whether one uses a computer or not, and the machine does not confer any greater degree of precision to the final results. However, the arrival of the computer has led to the calculation of many nutrients which would have been omitted in the days of hand calculation on the grounds that the effort was not worth while because analytical data were not reliable or even appropriate. It is now all too easy to produce masses of results of dubious reliability and so extensive that they exceed the powers of man to interpret. Here again the biologist scores over the professional programmer in as much as he knows what degree of accuracy is meaningful, and the appropriate way of setting out results in the print-up for easy comprehension. In our work we decided to present our results as both daily intakes and weekly means. The former are of value for checking on obvious coding errors, and for correlations with daily biochemical and physiological measurements: they were also useful in encouraging our subjects to overeat by showing them their performance on the previous day. However, the weekly means are more valid in assessing most experimental regimens.

Once checked, the numerical information in the diet books is punched on to paper tape with codes for subject and day numbers, and this is fed into the computer together with the appropriate programme. There are four main possibilities.

(I) General nutrients. This programme tabulates total calories, and their distribution into fat, carbohydrate and protein. Two measurements of protein quality are given together with nitrogen and sulphur intakes. Four minerals, iron, sodium, potassium and calcium are listed. This has been our most useful and widely used programme.

(2) Carbohydrates. One of the main interests of our department is the relationship between dietary carbohydrates and disease. This required a special programme and 
accompanying food table. We kept to the same code numbers so that the data tapes could be used for any of our programmes. The print-up shows sucrose intake divided into refined sugar consumed either from the sugar bowl or incorporated into processed foods, together with that occurring naturally. Also shown are intakes of free and bound glucose and fructose; galactose and lactose. Totals of sugar, starch and carbohydrate are also tabulated.

(3) Vitamins. Under some pressure we have produced a programme tabulating intakes of thiamine, riboflavine, nicotinic acid, ascorbic acid, retinol and calciferol. Our resistance was based on the poor data available for the vitamin content of foods owing to variations due to the effects of cultivation, season, storage and cooking. However, if the same programme is used in control and experimental situations the results are at least relative if not absolute and the programme has proved useful.

(4) Food categories. Another interest in our department is social nutrition, and factors determining food habits. We constantly stress that people eat foods not nutrients, and this prompted us to produce a programme to give information about the types of food consumed. It tabulates quantities of meat, cheese, eggs, fish, milk, butter, potatoes, breads, cereals, sugar, sweets, jams, cakes, puddings, tinned fruit, fruit and vegetables. This programme has also proved useful in observing the way people respond to dietary restrictions.

The above are our main programmes, but we also have some which are simple modifications of existing programmes to deal with special problems such as lowsodium diets, zoo diets, historical diets, etc. These by definition are used infrequently but were devised with a minimum of effort.

\section{Diet formulation}

The techniques used for the formulation of animal diets are not directly applicable to man because of the difficulty of introducing restrictions for palatability and individual food preferences. There have appeared reports in lay publications suggesting that the cost of catering in hospitals could be reduced by computer menu planning, but so far as one can judge the method involves the selection of dishes in a fairly random way and the computer is used to prevent bizarre combinations. Our interpretation of these reports is that the objectives have not been properly stated and that the results have not so far been widely applied. There would appear to be two areas in which the computer can assist, namely the selection of foods for the preparation of special diets and secondly the construction of least-cost diets.

In human experiments we have required diets high or low in $\mathrm{N}, \mathrm{Na}$, fat and carbohydrate, and have used our computer to select foods suitable for our purposes. In each case we related each nutrient to the energy content of the food and instructed the computer to pick out those foods which fell within given limits. Such foods could be consumed ad lib. to provide the necessary regimen, on the assumption that the total daily calorie intake is fixed. It is true that other foods could be used provided they were consumed in small amounts, but it is clear that the major part of the diet must be composed of the selected foods. Thus a diet limited to $40 \mathrm{~g}$ of protein and $2500 \mathrm{kcal}$ daily is more easily constructed from a knowledge of foods 
containing protein $<7 \%$ of the calories than by trial and error exercises using small amounts of high-protein foods mixed with foods containing no protein. Most dietary formulations are of this type, since the specification normally assumes an adequate calorie intake.

Such exercises are quite revealing and suggest that some of the classical ideas of food groups found in standard text books need modification (see Table 1). For example, cheese, eggs and many meats appear in the high-fat ( $>75 \%$ of calories) list and are not classified as high-protein foods (>50\% of calories). In Table 2 we

Table I. Foods selected for high protein, fat or carbohydrate content

$\begin{array}{lll}\begin{array}{c}\text { High-protein } \\ \left(>50^{*}\right.\end{array} & \begin{array}{c}\text { High-fat } \\ (>75 \% *)\end{array} & \begin{array}{c}\text { High-carbohydrate } \\ \left(>85 \%{ }^{*}\right)\end{array} \\ \text { Shellfish } & \text { Cheese } & \text { Sugar } \\ \text { Steamed fish } & \text { Butter } & \text { Bread } \\ \text { Tinned salmon } & \text { Cream } & \text { Tinned fruit } \\ \text { Boiled beef } & \text { Fried eggs } & \text { Potatoes } \\ \text { Veal } & \text { Bacon } & \text { Honey } \\ \text { Kidneys } & \text { Ham } & \text { Boiled sweets } \\ \text { Chicken } & \text { Mutton chops } & \text { Bananas } \\ \text { Tripe } & \text { Pork chops } & \text { Baked beans } \\ \text { Sweetbreads } & \text { Luncheon meat } & \text { Spaghetti } \\ \text { Rabbit } & \text { Almonds } & \text { Jellies } \\ & * \% \text { of calories. }\end{array}$

Table 2. Foods selected for low nitrogen or low sodium content

\begin{tabular}{lccc}
\multicolumn{1}{c}{ Food } & $\begin{array}{c}\text { Low-N } \\
(<2 \cdot 8 \mathrm{mg} / \mathrm{kcal})\end{array}$ & $\begin{array}{c}\text { Low-Na } \\
(<0 \cdot 10 \mathrm{mg} / \mathrm{kcal})\end{array}$ & Both \\
Cereals (66) & 9 & 34 & 2 \\
Dairy (37) & 4 & 2 & 0 \\
Fats and oils (7) & 7 & 6 & 6 \\
Meats (85) & 0 & 0 & 0 \\
Fish (95) & 0 & 0 & 0 \\
Fruit (82) & 44 & 53 & 38 \\
Nuts (10) & 4 & 9 & 3 \\
Vegctables (85) & 6 & I6 & 5 \\
Preserves (30) & 27 & I 2 & I I \\
Beverages (48) & 33 & I I & IO
\end{tabular}

The values indicate the number of foods selected by category from the food tables of McCance \& Widdowson ( 1960 ) to meet the criteria stated. The figures in parentheses refer to the number of foods in each category.

show the numbers of foods in the McCance \& Widdowson food tables that are suitable for use in preparing low- $\mathrm{N}(<7 \%$ of protein calories) and low- $\mathrm{Na}(<0 \cdot 10$ $\mathrm{mg} / \mathrm{kcal}$ ) diets, and these demonstrate the wide variety of foods available from which we have been able to prepare palatable regimens. However, we did experience difficulty in preparing acceptable menus for overeating subjects when both $\mathrm{N}$ and $\mathrm{Na}$ were restricted. This type of calculation is the first stage in the use of the computer for diet formulation. In the final analysis the construction depends upon an interaction between the dietitian and the individual with his marked food preferences.

One of our colleagues, Dr Watson, has prepared a programme to take this one 
Table 3. The cost of nutrients as purchased in different foods

\begin{tabular}{|c|c|c|c|c|c|c|c|}
\hline Food & $\begin{array}{l}\text { Price } \\
\text { (d./lb) }\end{array}$ & $\begin{array}{c}\text { Calories } \\
\text { (d./2500 } \\
\text { kcal) }\end{array}$ & $\begin{array}{l}\text { Protein } \\
\text { (d./50 g) }\end{array}$ & $\begin{array}{c}\text { Calcium } \\
\text { (d./500 } \\
\text { mg) }\end{array}$ & $\begin{array}{l}\text { Iron } \\
\text { (d./ro mg) }\end{array}$ & $\begin{array}{c}\text { Vitamin A } \\
\text { (d./5000 } \\
\text { i.u.) }\end{array}$ & $\begin{array}{l}\text { Vitamin C } \\
\text { (d. } / 20 \mathrm{mg})\end{array}$ \\
\hline Lard & I3 & 8 & $\infty$ & $\infty$ & $\infty$ & $\infty$ & $\infty$ \\
\hline Flour & 6 & 10 & 6 & 6 & 8 & $\infty$ & $\infty$ \\
\hline Cooking fat & 18 & II & $\infty$ & $\infty$ & $\infty$ & $\infty$ & $\infty$ \\
\hline Oatmeal & 9 & $\mathbf{x 2}$ & 8 & I 8 & $\mathbf{5}$ & $\infty$ & $\infty$ \\
\hline Sugar. & 9 & 12 & $\infty$ & 685 & $\infty$ & $\infty$ & $\infty$ \\
\hline Margarine & 18 & $\mathbf{I} 3$ & $\infty$ & 469 & 125 & 7 & $\infty$ \\
\hline Rice & II & 17 & 20 & $3+3$ & 53 & $\infty$ & $\infty$ \\
\hline Potatoes & 3 & I9 & I6 & 43 & 9 & $\infty$ & $0 \cdot 7$ \\
\hline Spaghetti & 14 & 20 & 15 & 66 & 25 & $\infty$ & $\infty$ \\
\hline Bread & 9 & $2 \mathbf{I}$ & $\mathbf{I 3}$ & I I & II & $\infty$ & $\infty$ \\
\hline Butter & 40 & 28 & $\infty$ & 3125 & $\infty$ & I3 & $\infty$ \\
\hline Syrup & I 5 & 30 & $\infty$ & 63 & 23 & $\infty$ & $\infty$ \\
\hline Cornflour & 34 & 35 & $\infty$ & 775 & 33 & $\infty$ & $\infty$ \\
\hline Jam & I7 & 35 & 265 & 78 & 25 & $\infty$ & $7 \cdot 5$ \\
\hline Cornflakes & 25 & 38 & $4 \mathrm{I}$ & $37^{\circ}$ & I9 & $\infty$ & \\
\hline Sausages & 34 & 38 & 24 & 104 & $\mathbf{r}_{4}$ & $\infty$ & $\infty$ \\
\hline Peanuts & 28 & $3^{8}$ & I6 & 74 & 44 & $\infty$ & $\infty$ \\
\hline Haricot beans & I 8 & $3^{8}$ & 9 & II & 6 & $\infty$ & $\infty$ \\
\hline Boiled sweets & 24 & 40 & $\infty$ & 535 & $\mathrm{r} 25$ & $\infty$ & $\infty$ \\
\hline Mutton & 20 & 45 & 12 & 59 & 9 & $\infty$ & $\infty$ \\
\hline Toffees & 36 & 45 & 190 & 42 & 52 & $\infty$ & $\infty$ \\
\hline Cheese & 38 & 50 & 17 & 5 & 148 & 30 & $\infty$ \\
\hline Bacon & $3^{6}$ & 55 & 27 & 274 & 75 & $\infty$ & $\infty$ \\
\hline Ham & 54 & 58 & 39 & 422 & 99 & $\infty$ & $\infty$ \\
\hline Brazil nuts & 30 & 58 & 50 & 42 & 52 & $\infty$ & $\infty$ \\
\hline Milk chocolate & 60 & $5^{8}$ & 75 & 25 & 77 & 2970 & $\infty$ \\
\hline Milk. & $9 / \mathrm{pt}$ & 60 & 25 & 7 & 225 & 64 & $\infty$ \\
\hline Herrings & 24 & 73 & 21 & 34 & 44 & 225 & $\infty$ \\
\hline Almonds & 30 & 75 & 43 & 36 & 43 & $\infty$ & $\infty$ \\
\hline Gelatin & $5^{6}$ & 78 & 6 & $\infty$ & $\infty$ & $\infty$ & $\infty$ \\
\hline Eggs & $33 /$ doz & $7^{8}$ & 21 & $4 x$ & I98 & 25 & $\infty$ \\
\hline Apples & 8 & 95 & 250 & 250 & 63 & 525 & 8 \\
\hline Sardines & 55 & 103 & 30 & $\mathbf{I 5}$ & 304 & 605 & $\infty$ \\
\hline Liver & 34 & 130 & 23 & 442 & $\mathbf{5}$ & 2 & $5 \cdot 0$ \\
\hline Carrots & 5 & I 30 & 80 & 12 & I9 & $\mathbf{I}$ & 37 \\
\hline Cabbage & 6 & 135 & 24 & 9 & I I & 40 & 0.5 \\
\hline Bananas & 12 & I 45 & 190 & 335 & 107 & 200 & 9 \\
\hline Beef & 48 & 150 & 27 & 1000 & 25 & $\infty$ & $\infty$ \\
\hline Pork & 32 & 150 & 16 & 840 & $5 \mathrm{I}$ & $\infty$ & $\infty$ \\
\hline Chicken & I8 & 170 & 17 & $66 \circ$ & 107 & $\infty$ & $\infty$ \\
\hline Onions & 8 & 178 & 85 & 28 & $5^{6}$ & $\infty$ & $3 \cdot 6$ \\
\hline Kippers & 30 & 183 & 32 & I I 4 & $\mathrm{IO}_{4}$ & 490 & $\infty$ \\
\hline Pears & I 5 & 213 & 470 & 235 & 156 & 3000 & 22 \\
\hline Oranges & Io & 215 & r 95 & 37 & 92 & 540 & $\mathbf{r} \cdot \mathbf{2}$ \\
\hline Beer & $18 / \mathrm{pt}$ & 250 & $64^{\circ}$ & r45 & $\infty$ & & $\infty$ \\
\hline $\mathrm{Cod}$ & 38 & 258 & 24 & 284 & 169 & $\infty$ & $\infty$ \\
\hline Frozen peas & 36 & 308 & 70 & $25^{8}$ & 42 & 24 & 0.6 \\
\hline Haddock & 44 & 345 & $3 \mathrm{I}$ & I 53 & 98 & $\infty$ & $\infty$ \\
\hline Pheasant & 90 & 370 & $5^{\circ}$ & 319 & 38 & $\infty$ & $\infty$ \\
\hline Tomatoes & Io & 390 & 100 & 82 & 53 & 29 & $2 \cdot 2$ \\
\hline Plaice & 66 & 470 & 48 & 439 & 179 & & $\infty$ \\
\hline Salmon & 152 & 663 & 140 & 915 & 649 & 845 & $\infty$ \\
\hline Spinach & 35 & 780 & 80 & 7 & r9 & $\begin{array}{r}\mathbf{1 2} \\
\infty\end{array}$ & $2 \cdot 6$ \\
\hline Whisky & $534 / \mathrm{bt}$ & 795 & $\infty$ & $\infty$ & $\infty$ & $\infty$ & $\infty$ \\
\hline Watercress & 24 & 938 & 90 & 12 & 33 & $\begin{array}{r}16 \\
\infty\end{array}$ & $\begin{array}{r}1 \cdot 7 \\
\infty\end{array}$ \\
\hline Winkles & $20 / \mathrm{pt}$ & 1030 & I IO & I 9 & $\begin{array}{r}23 \\
137\end{array}$ & & \\
\hline $\begin{array}{l}\text { Frozen beans } \\
\text { Mushrooms }\end{array}$ & $\begin{array}{l}46 \\
48\end{array}$ & $\begin{array}{l}1805 \\
3750\end{array}$ & $\begin{array}{l}480 \\
300\end{array}$ & $\begin{array}{r}\text { I } 52 \\
1880\end{array}$ & $\begin{array}{l}137 \\
104\end{array}$ & $\begin{array}{r}103 \\
\infty\end{array}$ & $\begin{array}{r}20 \\
\infty\end{array}$ \\
\hline Oysters & $90 / \mathrm{doz}$ & 6250 & 835 & 33 10 & 250 & 2940 & $\infty$ \\
\hline
\end{tabular}

Foods shown in bold type provide three or more of the nutrients at the cheapest rates. The ten cheapest rates for each nutrient are also given in bold type.

d., old pence. 
stage further. In operation, the dietitian will roughly construct a diet from the selected foods to meet the individual's requirement, then enter it into the computer which would not only calculate the nutrient content but would note deficiencies or excesses and suggest foods to correct these. The dietitian could then amend the diet accordingly, and thus build up a palatable mixture of the desired composition: and the whole process can be carried out at the keyboard. We feel that this dialogue between computer and dietitian is essential if both doctor and patient are to be satisfied.

Similar considerations apply to least-cost diets. In March 1965 we bought the range of foods given in Table 3 at the lowest price we could find. We express our findings in terms of price per daily requirement of six key nutrients. It is not surprising that the list demonstrates the advantages of wheat, oats and potatoes as providers of the major nutrients, since the peasant populations of England, Scotland and Ireland respectively existed on these staple foods for centuries. At the other end of the scale there are some odd anomalies such as that the costs of calories from chicken and onions are of the same order, as are the costs of protein from beer and oysters. Armed with the information provided in Table 3 it is possible to compute nutritionally adequate but appalling diets for less than I shilling and 6 pence/d (Table 4 ). The major outlay is for calories and protein, whereas the vitamin and mineral requirements can be satisfied with a few pennyworth of liver, carrots or cabbage: in fact, most vitamin requirements can be met by capsules at 0.18 pence/ d. Such exercises only go to show that the most cconomical catering officer spends

\section{Table 4. The nutrient content of some low-cost diets}

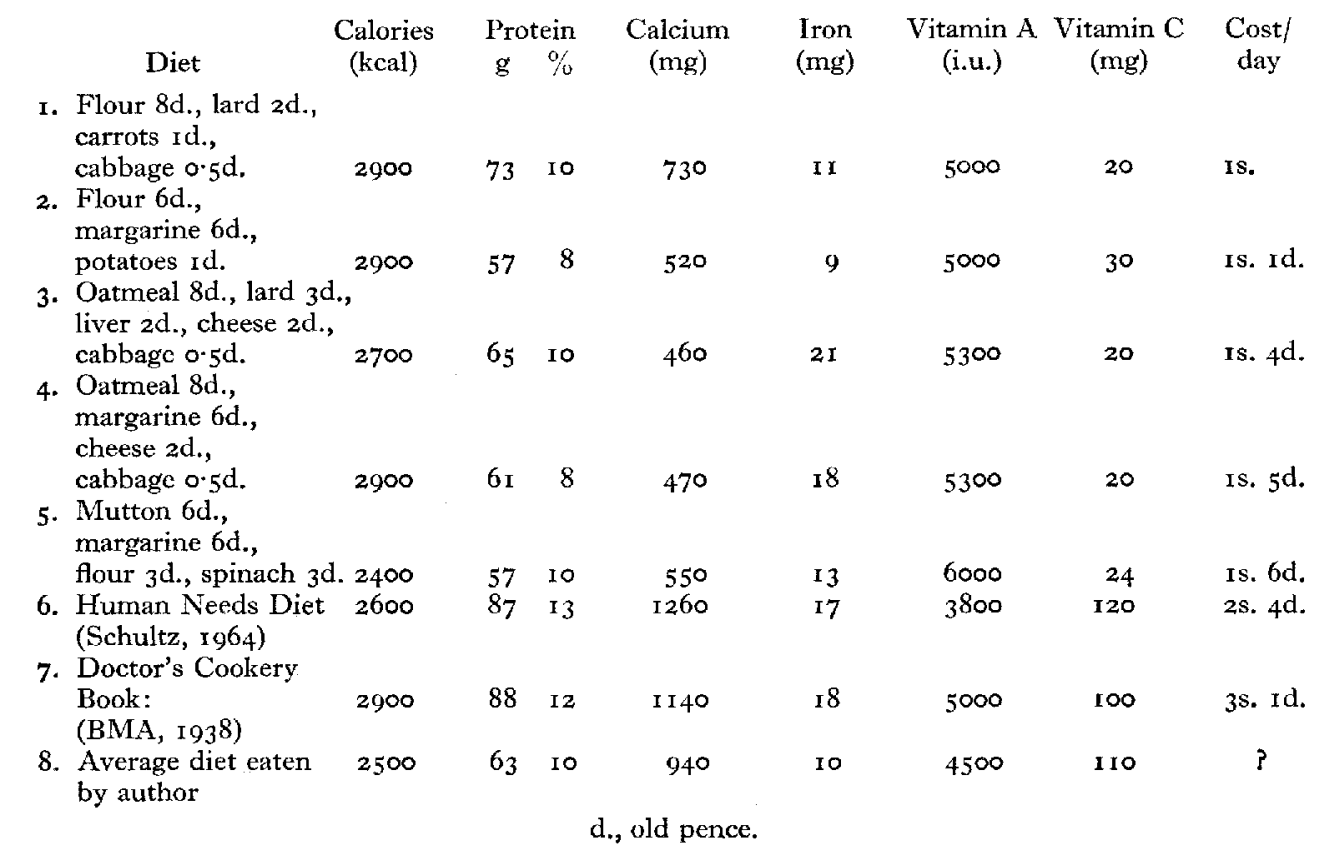


less than $25 \%$ of his money on nutrients and the rest on palatability. His problem could be solved by methods outlined above for the dietitian.

We are grateful to Dr Watson for helpful suggestions in the preparation of this paper.

\section{REFERENCES}

British Medical Association (1938). Doctor's Cookery Book. London: British Medical Association. McCance, R. A. \& Widdowson, E. M. (1960). Spec. Rep. Ser. med. Res. Conn. no. 297.

Schultz, T. ( 1964). Human Needs Diet. Oxford University Institute of Economics and Statistics (mimeo.).

\section{Farm policies for the feeding of livestock}

\section{By S. C. Thompson, Department of Agriculture, University of Reading}

The animal feeds industry has known for some 25 years how to formulate a compound diet which conforms to a set of minimum or maximum nutrient constraints, and to ensure that the ingredients are chosen in such a way as to minimize the cost per ton of the resulting compound. The computer technique of linear programming has been in use for over Io years by the larger firms as a routine step in diet formulation, and it is accepted practice in England that minimum or maximum percentages of the more important nutrients are printed on the bag.

However, as Dent \& Casey ( 1967 ) remind us, animals do not eat percentages, but measurable weights of nutrients per day; and the total weight of the feed in which these nutrients are carried may be of secondary importance. Limits on voluntary intake will certainly impose extra constraints on the formulation of a ration but these will be by no means as rigid as the specification of fixed nutrient percentages. Formulation of a ration in terms of daily requirement for calories, amino acids, vitamins and minerals is no more complex a problem than that which faces the commercial compounder. $A$ linear programme can be used to devise both daily rations and percentage diets.

\section{Non-ruminant rations}

Dent (1964) took the question of ration formulation a step further by putting into an explicit form the notion that nutrients might substitute (in the economic sense) for one another while still producing a similar amount of end-product. Analysing results from growing pigs, he produced a series of functions relating daily live-weight gain, energy intake and crude protein intake. A stylised graph of one relationship is reproduced as Fig. I.

Two questions now present themselves to the stockman for simultaneous solution: what is the most desirable daily rate of gain; and for that gain, which particular combination of nutrients can be formulated most cheaply from the ingredients available? A least-cost ration for each of the three rates of gain drawn in Fig. I can 